\title{
Parent of Origin Effects in Attention/Deficit Hyperactivity Disorder (ADHD): Analysis of Data From the International Multicenter ADHD Genetics (IMAGE) Program
}

Richard J.L. Anney, ${ }^{1 *}$ Ziarih Hawi, ${ }^{1}$ Karen Sheehan, ${ }^{1}$ Aisling Mulligan, ${ }^{1}$ Carlos Pinto, ${ }^{1}$ Keeley J. Brookes, ${ }^{2}$ Xiaohui Xu, ${ }^{2}$ Kaixin Zhou, ${ }^{2}$ Barbara Franke, ${ }^{3,4}$ Jan Buitelaar, ${ }^{3}$ Sita H. Vermeulen, ${ }^{4,5}$ Tobias Banaschewski, ${ }^{6}$ Edmund Sonuga-Barke, ${ }^{8}$ Richard Ebstein, ${ }^{9}$ Iris Manor, ${ }^{10}$ Ana Miranda, ${ }^{11}$ Fernando Mulas, ${ }^{11}$ Robert D. Oades, ${ }^{12}$ Herbert Roeyers, ${ }^{13}$ Nanda Rommelse, ${ }^{14}$ Aribert Rothenberger, ${ }^{7}$ Joseph Sergeant, ${ }^{14}$ Hans-Christoph Steinhausen, ${ }^{15}$ Eric Taylor, ${ }^{2}$ Margaret Thompson, ${ }^{8}$ Philip Asherson, ${ }^{2}$ Stephen V. Faraone, ${ }^{16}$ and Michael Gill ${ }^{1}$

\section{American Journal of Medical Genetics Part B 147B: 1495-1500}

This is the reformatted manuscript submitted - prior to publication in its final form at DOI 10.1002/ajmg.b.30659

1 Department of Psychiatry, Trinity College Dublin, St. James's Hospital, Dublin 8, Ireland

* Corresponding author E-mail: anneyr@tcd.ie

2 MRC Social Genetic Developmental and Psychiatry Centre, Institute of Psychiatry, London, UK

3 Department of Psychiatry, Radboud University Nijmegen Medical Centre, Nijmegen, The Netherlands

4 Department of Human Genetics, Radboud University Nijmegen Medical Centre, Nijmegen, The Netherlands

5 Department of Epidemiology and Biostatistics, Radboud University Nijmegen Medical Centre, Nijmegen, The Netherlands

6 Department of Child and Adolescent Psychiatry and Psychotherapy, Central Institute of Mental Health, Mannheim, Germany

7 Child and Adolescent Psychiatry, University of Göttingen, Göttingen, Germany

8 School of Psychology, University of Southampton, Highfield, Southampton, UK

9 S Herzog Memorial Hospital, Jerusalem, Israel

10 ADHD Clinic, Geha Mental Health Center, Petak-Tikvah, Israel

11 Department of Developmental and Educational Psychology, University of Valencia, Valencia, Spain

12 University Clinic for Child and Adolescent Psychiatry, Essen, Germany

13 Department of Experimental Clinical Health Psychology, Ghent University, Ghent, Belgium

14 Vrije Universiteit, De Boelelaan, Amsterdam, Holland

15 Department of Child and Adolescent Psychiatry, University of Zurich, Zurich, Switzerland

16 Departments of Psychiatry and Neuroscience and Physiology, SUNY Upstate Medical University, Syracuse, New York

KEY WORDS: ADHD; candidate gene; parent of origin effect

ACKNOWLEDGMENTS: The IMAGE project is a multisite, international effort supported by NIH grant R01MH62873 to S.V. Faraone. Site Principal Investigators are Philip Asherson, Tobias Banaschewski, Jan Buitelaar, Richard P. Ebstein, Stephen V. Faraone, Michael Gill, Ana Miranda, Fernando Mulas, Robert D. Oades, Herbert Roeyers, Aribert Rothenberger, Joseph Sergeant, Edmund Sonuga-Barke, and Hans-Christoph Steinhausen. Senior co-investigators are Margaret Thompson, Pak Sham, Peter McGuffin, Robert Plomin, lan Craig and Eric Taylor. Chief Investigators at each site are Rafaela Marco, Nanda Rommelse, Wai Chen, Henrik Uebel, Hanna Christiansen, Ueli Mueller, Cathelijne Buschgens, Barbara Franke, Lamprini Psychogiou. We thank all the families who kindly participated in this research.

GRANT SPONSOR: NIH; Grant number: R01MH62873. 


\section{ABSTRACT}

There are conflicting reports suggesting that the parental origin of transmitted risk alleles may play a role in the etiology of attention deficit/hyperactivity disorder (ADHD). A recent report by Hawi and colleagues observed a generalized paternal over-transmission of alleles associated with ADHD. This was not replicated in more recent studies. Using data from a large multicenter study we examined the overall and gene specific parent of origin effect in 554 independent SNPs across 47 genes. Transmission disequilibrium and explicit parent of origin test were performed using PLINK. Overall parent of origin effect was tested by Chisquare. There was no overall parent of origin effect in the IMAGE sample $\left(\chi^{2}{ }_{1}=1: 82, P=\right.$ $0.117)$. Five markers in three genes, DDC, TPH2, and SLC6A2 showed nominal association $(\mathrm{P}<0.01)$ with $A D H D$ combined subtype when restricted to maternal or paternal transmission only. Following the initial report by Hawi and co-workers three studies, including this one, found no evidence to support an overall parent of origin effect for markers associated with ADHD. We cannot however, exclude gene-specific parent of origin effect in the etiology ADHD.

There is considerable evidence to suggest that expression of particular genes can be influenced by their parental origin. The parent of origin effect cannot be explained through inheritance of differences in DNA sequences alone, but requires additional mechanisms to be evoked. These mechanisms are broadly termed "epigenetic inheritance." Epigenetic inheritance includes stable and heritable alterations of the genetic code, not including change at the DNA sequence. The epigenetic marking of genes altering their expression can be achieved through a number of mechanisms. To date epigenetic modification has been described at the chromatin- and nucleotide-level. The complex packaging of DNA into chromatin and chromosomes is maintained by the histone proteins. Consequently, the histone proteins are integral to the regulation of access to the DNA sequence and therefore the expression of genes maintained within these structures. Modifications of histone proteins can include acetylation, methylation, phosphorylation, and ubiquitination [Jaenisch and Bird, 2003]. However, the most notable epigenetic modification occurs at the nucleotide level through methylation of the nucleotide base cytosine. The methylation of cytosine residues at the gene promoter is thought to decrease the transcriptional activity of a gene [Robertson, 2005]. Imprints are removed during early germ cell development, re-established later in germ cell development or after fertilization, and maintained during embryonic development. "Imprinting" of the gene effectively tells the molecular machinery within the cell to express only one allele in the cell and its progeny. There is evidence to suggest that nearly 80 human genes show mono-allelic expression consistent with imprinting [Jirtle, 2002]. The mechanism underlying the reading of the imprint can involve many aspects of gene expression, and the silencing can be stable throughout the individual's life [Federman, 2006].

A high proportion of the imprinted genes that have been identified are highly expressed in the central nervous system and encompass a wide variety of functions including intracellular signaling, RNA processing and neurotransmitter signaling [Davies et al., 2005]. Interestingly, involvement of imprinting has been suggested for a number of common mental disorders, including autism, bipolar 
disorder, schizophrenia, and Tourette's syndrome. The evidence for this has arisen from observed preferential inheritance of risk alleles from either the maternal or paternal line. Imprinting is only one mechanism contributing to these disorders. However, we must also consider the influence of other biological influences such as the variation in maternally inherited mitochondrial DNA and in utero maternal environment [Weinberg, 1999].

There is evidence to suggest that the parental origin of genetic risk factors may play a role in the etiology of attention deficit/hyperactivity disorder [ADHD (MIM143465)]. ADHD is typically characterized by inattention, excessive motor activity, impulsivity, and distractibility. Individuals with ADHD have significant impairment in family and peer relations. Moreover, they have difficulties in academic functioning and show high comorbidity with antisocial, mood, anxiety, and substance use disorders. ADHD is a common disorder with a prevalence of European children estimated at between 4.6\% [Polanczyk et al., 2007]. Family, twin, and adoption studies strongly support the influence of genetic factors in the etiology of ADHD [Thapar et al., 1999; Asherson, 2004; Faraone et al., 2005]. However, the specific mode of inheritance is unknown.

There have been many association studies examining the role of individual candidate genes in ADHD. Meta-analysis of these data suggests that variation in the genes that code for the dopamine receptors D4 (DRD4) and D5 (DRD5), the 5-hydroxytryptamine (serotonin) transporter (SLC6A4), the serotonin 1B receptor (HTR1B), synaptosomal protein of $25 \mathrm{kD}$ (SNAP25) and the dopamine transporter [SLC6A3 (DAT1)] influence susceptibility to ADHD [Faraone et al., 2005]. In examination of putative risk alleles, Hawi and colleagues observed a generalized parent of origin effect in an Irish ADHD study. Using data from genetic variants that showed at least a trend toward association with ADHD $(\mathrm{P}<0.01)$ they observed that the previously identified risk allele was more likely to be transmitted with the paternal chromosome than the maternal chromosome (paternal vs. maternal w21\%49.6; P1/40.0019) [Hawi et al., 2005]. More recently, two further studies have failed to confirm an overall paternal origin effect [Kim et al., 2007; Laurin et al., 2007a]. Gene-specific parent of origin effects have been observed for BDNF [Kent et al., 2005], DDC [Hawi et al., 2001], GNAL [Laurin et al., 2007b], HTR1B [Hawi et al., 2002], SLC6A4 [Hawi et al., 2005; Banerjee et al., 2006], SNAP25 [Mill et al., 2004], TPH2, DRD4, DRD5, and SLC6A3 [Hawi et al., 2005].

This report describes findings of a test for overall and gene specific parent of origin effects in 47 autosomal genes examined in the large International Multicenter ADHD Genetics (IMAGE) study.

The participants described in this manuscript have previously been reported by the IMAGE consortium [Brookes et al., 2006]. Ethical approval for the study was obtained from National Institute of Health registered ethical review boards for each center. Sample collection, SNP selection and genotyping described in this manuscript have previously been reported by the IMAGE consortium [Brookes et al., 2006]. Candidate genes were selected according to a "biological systems" approach. Forty-six genes were identified that play important roles in the regulation of dopamine, serotonin, and norepinephrine neurotransmission. A further six genes important in circadian rhythm were also selected. Genes fell into the following functional groups: dopamine receptors, serotonin receptors, norepinephrine 
receptors, neurotransmitter metabolic and catabolic enzymes, neuronal transporters, synaptic vesicle associated proteins, fatty acid desaturase enzymes and circadian rhythm genes. For detailed summary of these genes see Brookes et al. [2006]. Genes located on the Xchromosome were not examined in the parent of origin analysis. The decision not to analyze female probands for transmission from the X-chromosome was made to prevent confounding by $\mathrm{X}$ inactivation.

Pair-wise linkage disequilibrium statistics were calculated using PWLD in STATA9 [Clayton, 2002]. Transmission disequilibrium test and explicit parent of origin test were performed using PLINK [Purcell et al., 2007]. To exclude bias due to non-independence of the tested markers we performed parent of origin analysis on a pruned subset of SNPs that were in approximate linkage equilibrium with each other. Markers were pruned where they showed a variance inflation factor (VIF) of 2 or greater. A VIF of 1 would imply that the SNP is completely independent of all other SNPs [Purcell et al., 2007]. Additional quality control parameters for the data were applied within PLINK. Fifty-two individuals with _90\% completed genotyping across the SNP panel were excluded. After pruning the final analysis was performed across 554 SNPs in 590 nuclear families, accounting for 659 affected offspring trios. For comparative analysis data from the non-pruned set of 905 SNP markers were examined along side SNP data from five published studies [Hawi et al., 2005; Kent et al., 2005; Kim et al., 2007; Laurin et al., 2007a, b].

Five markers showed an association with ADHD-CT at the unadjusted $\mathrm{P}<0.01$ level. Using the explicit parent of origin test, none show a significant difference in the transmission from the maternal and the paternal lineage (see Table I). An overall parent of origin effect was examined by comparing all maternal and paternal transmissions in the five associated markers. There was no overall parent of origin effect in these data $\left(\chi^{2}{ }_{1}=\right.$ $1: 82, P=0.117)$. Five additional markers showed association with ADHD-CT when restricted to maternal or paternal transmission only (see Table II). Using the explicit parent of origin test on these SNPs only the dopamine decarboxylase (DDC) linked marker rs11575454 showed a weak parent of origin effect $(P=0.039)$.

In the explicit parent of origin analysis, two additional markers showed nominally significant parent of origin effects at $\mathrm{P}<0.01$. These were rs518511 and rs3730315 linked to the FADS2 gene on chromosome 11 and ADRBK2 on chromosome 22, respectively. Association with ADHD for rs518511 was due to paternal transmissions whilst association for rs3730315 occurred through maternal transmissions (see Table III). The parent of origin effects at these markers did not remain significant when corrected for the 545 comparisons examined in the "pruned" dataset.

To date a number of reports have described markers showing a parent of origin effect in ADHD. As mentioned above, three studies have examined overall parent of origin effects in ADHD [Hawi et al., 2005; Kim et al., 2007; Laurin et al., 2007a]. Additional gene-specific parent of origin effects has been observed for BDNF [Kent et al., 2005], DDC [Hawi et al., 2001], GNAL [Laurin et al., 2007b], HTR1B [Hawi et al., 2002], SLC6A4 [Hawi et al., 2005; Banerjee et al., 2006], SNAP25 [Mill et al., 2004], TPH2, DRD4, DRD5, and SLC6A3 [Hawi et al., 2005]. In a post-hoc analysis we tested whether markers examined in more than one study showed evidence of a parent of origin effect (see Table IV). Briefly, 7 SNP markers across 
TABLE L. Summary of Transmission Disequilibrium Test and Parent of Origin Analysis in Markers Showing Nominal Association in the IMAGE Sample at $P<0.01$

\begin{tabular}{|c|c|c|c|c|c|c|c|c|c|c|c|c|c|c|c|c|c|c|c|c|c|c|}
\hline \multirow[b]{2}{*}{ CIIR } & \multirow[b]{2}{*}{ Ponition } & \multirow[b]{2}{*}{ Gene } & \multirow[b]{2}{*}{ Marker } & \multirow[b]{2}{*}{ GT } & \multirow[b]{2}{*}{ Rizk } & \multicolumn{5}{|c|}{ 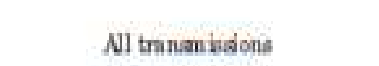 } & \multicolumn{5}{|c|}{ Matemal tranimiarionis only } & \multicolumn{5}{|c|}{ Patemal trananiacion only } & \multicolumn{2}{|c|}{$\begin{array}{c}\text { Pamant of origin } \\
\text { effed }\end{array}$} \\
\hline & & & & & & $\mathrm{T}$ & NT & $x^{2}$ & OR & $P$ & T & $\mathrm{NT}$ & $x^{2}$ & $\mathrm{OR}$ & P & $T$ & $\mathrm{NT}$ & $x^{2}$ & OR & P & 7-score & $P$ \\
\hline 3 & 14489628 & SLC9A9 & $n=1242075$ & GA & G & 297 & 224 & 88 & 1.3 & 0.009 & 150 & 116 & 4.35 & 1.3 & 0.037 & 137 & 113 & 23 & 1.2 & 0.129 & -0.26 & 0.716 \\
\hline 3. & 195243944 & IIESI & 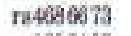 & GA & A & 302 & 239 & 73 & 1.3 & $0.00 \%$ & 163 & 120 & 6.53 & 1.4 & 0.011 & 139 & 120 & 1.4 & 1.2 & 0.298 & -0.92 & 0.358 \\
\hline 12 & 70641446 & TPIL & FB1386493 & Gis & A & 204 & 150 & 82 & 1.4 & 0.004 & 116 & 75 & 8.85 & 16 & 0.003 & 90 & 75.5 & 12 & 12 & 0.276 & -1.25 & 0.213 \\
\hline 17 & 4567246 & ARRB2 & nะ17208257 & GA & G & 101 & 67 & 69 & 15 & 0.009 & 53 & 36 & 3.25 & 1.5 & 0.072 & 48 & 31 & 3.7 & 15 & 0.056 & 0.16 & 0.873 \\
\hline 17 & 3507815 & PNMT & na200173 & GIA & A & 27 & 11 & 6.7 & 2.5 & 0.009 & 16 & 6 & 4.65 & 2.7 & 0,038 & 11 & 5 & 23 & 22 & 0.134 & -0.27 & 0.790 \\
\hline & & & & & NI & 921 & 69 & 32 & 1.3 & $1.4 \mathrm{E}-07$ & 498 & 353 & 24.7 & 1.4 & $4.9 \mathrm{E}-06$ & 425 & 35 & 83 & 1.2 & 1. $\mathrm{fE}-02$ & & $0.117^{\circ}$ \\
\hline
\end{tabular}

"Test is ativtic derived from $\chi^{2}$ of total matemal and paternal tranian iasiona.

TABLE II. Summary of Tranam ission Disexuilibrium Test and Parent of Origin Analysis in Markers Showing Naminal Associntion From Maternal-Only or Paternal-Only Transm issians in the IMAGE Sample at $P<0,01$

\begin{tabular}{|c|c|c|c|c|c|c|c|c|c|c|c|c|c|c|c|c|c|c|c|c|c|c|}
\hline \multirow[b]{2}{*}{ CIIR } & \multirow[b]{2}{*}{ Padtion } & \multirow[b]{2}{*}{ Gone } & \multirow[b]{2}{*}{ Marker } & \multirow[b]{2}{*}{ GT } & \multirow[b]{2}{*}{ Riak } & \multicolumn{5}{|c|}{ All tranamiaiona } & \multicolumn{5}{|c|}{ Mnternel tranamivdiona only } & \multicolumn{5}{|c|}{ Patemul tranamiaion onjy } & \multicolumn{2}{|c|}{$\begin{array}{c}\text { Parent of angen } \\
\text { offoct }\end{array}$} \\
\hline & & & & & & T & NT & $x^{2}$ & OR & $P$ & $\mathrm{~T}$ & NT & $x^{2}$ & OR & $P$ & $\mathrm{~T}$ & NT & $x^{2}$ & OR & $p$ & 7-acome & P \\
\hline 7 & 60322022 & DDC & $n 11575454$ & GIC & C & 21 & 9 & 3 & 2.3 & 0.028 & 12 & 1 & 9 & 12 & 0.002 & 9 & A. & 0.1 & 1.1 & 0.804 & -2.1 & 0.039 \\
\hline 7 & 50391415 & $\mathrm{DDC}$ & $n 1468163$ & GiA & A & 160 & 129 & 3 & 12 & 0.068 & 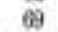 & 70 & 0 & 1 & 0.92 & 92 & 60 & 68 & 1.5 & 0.009 & 19 & 0,062 \\
\hline 12 & 70641446 & TPID & $m 1396493$ & GA & $A$ & 204 & 150 & 8. & 1.4 & 0.004 & 116 & 75 & 9. & 16 & 0.009 & 90 & 76 & 12 & 12 & 0.276 & -12 & 0.213 \\
\hline 12 & 79712221 & TPF2 & m1711947 & Gis & G & 175 & 134 & 5 & 1.3 & 0.020 & 100 & 66 & 7 & 15 & 0.009 & 76 & 69 & 0.3 & 1.1 & 0.560 & 14 & 0.164 \\
\hline 16 & 34252607 & SLCGAL & n3785143 & GiA & A & 130 & 95 & 5 & 1.4 & 0.020 & 56 & 51 & 0 & 11 & 0.629 & 75 & 4 & 8.1 & 1.7 & 0.094 & 16 & 0.105 \\
\hline
\end{tabular}

TABLE III. Summary of Tranamisan Disequilibrium Test and Parent of Orign Analysis in Markers Showing Naminal Parent of Origin Effects in the IMAGE Sumple at $P<0,01$

\begin{tabular}{|c|c|c|c|c|c|c|c|c|c|c|c|c|c|c|c|c|c|c|c|c|c|c|}
\hline \multirow[b]{2}{*}{ CAR } & \multirow[b]{2}{*}{ Pasition } & \multirow[b]{2}{*}{ Gene } & \multirow[b]{2}{*}{ Marker } & \multirow[b]{2}{*}{ GT } & \multirow[b]{2}{*}{ Rivk } & \multicolumn{5}{|c|}{ NI trananisiona } & \multicolumn{5}{|c|}{ Matermal tranamisaiona only } & \multicolumn{5}{|c|}{ Paternal tranemiasions only } & \multicolumn{2}{|c|}{$\begin{array}{c}\text { Parent of origin } \\
\text { effoct }\end{array}$} \\
\hline & & & & & & $\mathrm{T}$ & NT & $x^{2}$ & $\mathrm{OR}$ & p & $\mathrm{T}$ & NT & $x^{2}$ & OR & p & $\mathrm{T}$ & NT & $x^{2}$ & $\mathrm{OR}$ & p & Znowe & $p$ \\
\hline 11 & 61389030 & FADS2 & ra518511 & $A C$ & c & 123 & 120 & 0 & 1 & 0.847 & 47.5 & 67.5 & 3.5 & a. 7 & 0.062 & 76 & 58 & 4.1 & 1.4 & 0.04 & 2.74 & 0.006 \\
\hline 22 & 24424591 & ADRHK2 & та3790015 & GA & A & 31 & 27 & 03 & 1.1 & 0.699 & 19.5 & 7.5 & 8.3 & 26 & 0.021 & 12 & 20 & 21 & 0.69 & 0.15 & 2.61 & 0.009 \\
\hline
\end{tabular}

TABLE IV. Summary of Combined Tranamission Disequilibrium Test and Parent of Origin Statistios in SNP Markars Examined Acros Multiple Publisbed Studies

\begin{tabular}{|c|c|c|c|c|c|c|c|c|c|c|c|c|c|c|c|c|c|c|c|c|c|c|c|}
\hline \multirow[b]{2}{*}{ CIIR } & \multirow[b]{2}{*}{ Podtion } & \multirow[b]{2}{*}{ Gene } & \multirow[b]{2}{*}{ Murker } & \multirow[b]{2}{*}{ GT } & \multirow[b]{2}{*}{ Risk } & \multirow[b]{2}{*}{ Stady } & \multicolumn{5}{|c|}{ Ni tranamindions } & \multicolumn{5}{|c|}{ Matemad tramaniaiona only } & \multicolumn{5}{|c|}{ Puterval tranamiadina only } & \multicolumn{2}{|c|}{$\begin{array}{l}\text { Psament d } \\
\text { origin effect }\end{array}$} \\
\hline & & & & & & & $\mathrm{T}$ & NT & $x^{3}$ & $\mathrm{OR}$ & $P$ & $\mathrm{~T}$ & NT & $x^{2}$ & OR & P & $\mathrm{T}$ & $\mathrm{NT}$ & $x^{2}$ & $\mathrm{OR}$ & $P$ & $\dot{x}^{2}$ & $P$ \\
\hline 5 & 1447521 & SLOEAS & Bs87072 & NG & $\Lambda$. & sit & 201 & 242 & 3.8 & 0.83 & 0.05 & 94.5 & 131.5 & 4.7 & 0.75 & 0.03 & 1025 & 110.5 & 0.3 & 0.93 & 0.38 & 125 & 0.26 \\
\hline 6 & 78229978 & FTR1B & BS6296 & $0 \mathrm{C}$ & G & a.be & ang & 386 & 0.2 & 1.04 & 0.6 & 190 & 187 & 0.1 & 0.96 & 071 & 199 & 179 & 1.1 & 111 & a. 30 & 0.91 & 0.38 \\
\hline 11 & 27636491 & BDNF & ES62 & $\mathrm{AC}$ & $A$ & $=x$ & 244 & 862 & 0.6 & 0.93 & & 128.5 & 1135 & 0.4 & 109 & 0.52 & 115.5 & 1435 & s & 0.8 & 0.08 & 2.79 & 0.09 \\
\hline 12. & 70634964 & TPH 2 & P81843909 & $\mathrm{dA}$ & $\mathrm{c}$ & $a b$ & 229 & 151 & 16 & 1.52 & 1.0R -04 & 124.6 & 756 & 12 & 1.65 & 5. $0 \mathrm{E}-04$ & 1045 & 75.5 & 4.7 & 1.38 & 0.06 & 0.69 & 040 \\
\hline 13 & 46507034 & FTR2A & RS6314 & $\mathrm{AG}$ & A & $\rightarrow \infty$ & 182 & 148 & 0.9 & 0.99 & 0.34 & 70.5 & 765 & 0.2 & 0.92 & 0.62 & 615 & 715 & 0.8 & 0.86 & 0.39 & 0.05 & 0.83 \\
\hline 20 & 10164901 & SNNP2S & ES363026 & $\mathrm{AC}$ & $A$ & $=d$ & 100 & 117 & 1.3 & 0.85 & 0.25 & 42 & 51 & 0.9 & 0.82 & 0.35 & 68 & 66 & as & 0.88 & 0.47 & 0.06 & 0.81 \\
\hline 20 & 10206653 & SNAP2S & BS6039865 & $\mathrm{ch}$ & C & $\rightarrow \infty$ & 895 & 381 & 0.3 & 1.04 & 0.62 & 200.6 & 184.5 & 0.9 & 11 & as3 & 1915 & 196.5 & 0.1 & 097 & 0.80 & 0.68 & 0.41 \\
\hline
\end{tabular}

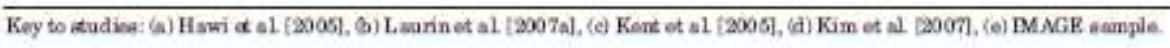


7 genes have been examined in the IMAGE and at least one other study. No evidence of a parent of origin effect was observed for any of the tested markers.

In conclusion, in this report we showed parent-specific associations with ADHD-CT $(P<0.01)$ for five independent markers linked to three genes, namely DDC, TPH2, and SLC6A2 (see Table II). Assuming all of the 554 markers are independent and a type 1 error of $1 \%$ we would expect to observe 11 associations from both the paternal and maternal transmissions by chance alone. This would suggest that these observations may be due to chance alone.

However, previous data from analysis of DDC show that the association signals are stronger from the paternal chromosome in ADHD [Hawi et al., 2001] and bipolar affective disorder [Borglum et al., 2003]. DDC is located on chromosome 7p11, 27kb from GRB10 (encoding growth factor receptor-bound protein 10), that has been demonstrated to be imprinted in various human and mouse tissues. Imprinting of GRB10 is partial with tissue and isoforms specificity [Blagitko et al., 2000]. Since imprinted genes are often found in clusters regulated by imprinting centers the DDC gene locus may also be imprinted. The direct examination of the imprinting status of the DDC gene shows evidence of asynchronous replication, a phenomenon suggestive of imprinting. However, SNP expression analysis shows biallelic expression of transcribed DDC SNPs in various human and mouse tissues, which is counter-indicative of imprinting [Hitchins et al., 2002]. The imprinting status of DDC is therefore not conclusive but does not exclude the possibility of partial or tissue and developmental phase specific imprinting for this gene. Tph1, the mouse homologue to human TPH1, shows some evidence of paternal imprinting in the mouse cerebellum using a custom murine chromosome 7 microarray [Buettner et al., 2004]. However, there is evidence to suggest that Tph1 is not expressed in the brain, and that the tryptophan hydroxylase in the brain is generated from Tph2 [Walther et al., 2003]. It would therefore be prudent to further examine the human TPH2 gene in cerebellum and other brain regions to examine potential imprints. Moreover, paternal imprinting of the TPH2 gene would support the association with ADHD stemming from transmission from the maternal chromosomes observed in this study.

Two markers showed an explicit parent of origin effect, namely markers linked to FADS2 and ADRBK2. However, it is important to consider that the significance of these findings is driven not only by an over-transmission of a putative risk allele from one parent but a combined undertransmission of the risk allele from the other parent. This would suggest conflicting selection at the maternal and paternal chromosome as opposed to a one-way selection bias as observed for DDC, TPH2, and SLC6A2 described above.

Data from the Irish ADHD study presented by Hawi et al. [2005] suggested that the risk alleles for ADHD are, in general, preferentially transmitted via the paternal chromosome. In three follow-up studies, including data presented here, no evidence to support an overall parent of origin effect for markers associated with ADHD was found. We cannot, however, exclude gene-specific parent of origin effects in the etiology ADHD.

\section{REFERENCES}

Asherson P. 2004. Attention-deficit hyperactivity disorder in the postgenomic era. Eur J Child Adolesc Psychiatry 13(Suppl 1):I50-170.

Banerjee E, Sinha $S$, Chatterjee A, Gangopadhyay PK, Singh M, 
Nandagopal K. 2006. A family-based study of Indian subjects from Kolkata reveals allelic association of the serotonin transporter intron-2 (STin2) polymorphism and attention-deficithyperactivity disorder (ADHD). Am J Med Genet Part B 141B (4):361-366.

Blagitko N, Mergenthaler S, Schultz U, Wollmann HA, Craigen W, Eggermann T, Ropers HH, Kalscheuer VM. 2000. Human GRB10 is imprinted and expressed from the paternal and maternal allele in a highly tissue- and isoform-specific fashion. Hum Mol Genet 9 (11):1587- 1595.

Borglum AD, Kirov G, Craddock N, Mors O, Muir W, Murray Y, McKee I, Collier DA, Ewald H, Owen MJ, et al. 2003. Possible parent-of-origin effects of Dopa decarboxylase in susceptibility to bipolar affective disorder. Am J Med Genet Part B 117B (1):18-22.

Brookes K, Xu X, Zhou K, Lowe N, Anney R, Franke B, Gill M, Ebstein R, Buitelaar J, Sham $P$, et al. 2006. The analysis of 51 genes in DSM-IV combined type attention deficit hyperactivity disorder: Association signals in DRD4, DAT1 and 16 other genes. Mol Psychiatry 11 (10): 934-953.

Buettner $\mathrm{VL}$, Longmate JA, Barish $\mathrm{ME}$, Mann JR, Singer-Sam J. 2004. Analysis of imprinting in mice with uniparental duplication of proximal chromosomes 7 and 15 by use of a custom oligonucleotide microarray. Mamm Genome 15 (3):199-209.

Clayton D. 2002. Clayton, Geneassoc: STATA modules for gene association analyses. Cambridge, UK; Cambridge Institute for Medical Research: (2002).

Davies W, Isles AR, Wilkinson LS. 2005. Imprinted gene expression in the brain. Neurosci Biobehav Rev 29 (3):421-430.
Faraone SV, Perlis RH, Doyle AE, Smoller JW, Goralnick JJ, Holmgren MA, Sklar P. 2005. Molecular genetics of attentiondeficit/hyperactivity disorder. Biol Psychiatry 57 (11):1313-1323.

Federman D. 2006. The biology of human sex differences. N Eng J Med 354 (14):1507-1514.

Hawi Z, Foley D, Kirley A, McCarron M, Fitzgerald M, Gill M. 2001. Dopa decarboxylase gene polymorphisms and attention deficit hyperactivity disorder (ADHD): No evidence for association in the Irish population. Mol Psychiatry 6 (4):420-424.

Hawi Z, Dring M, Kirley A, Foley D, Kent L, Craddock N, Asherson $\mathrm{P}$, Curran $\mathrm{S}$, Gould A, Richards S, et al. 2002. Serotonergic system and attention deficit hyperactivity disorder (ADHD): A potential susceptibility locus at the 5HT (1B) receptor gene in 273 nuclear families from a multi-centre sample. Mol Psychiatry 7 (7):718-725.

Hawi Z, Seguardo R, Conroy J, Sheehan K, Lowe N, Kirley A, Shields D, Fitzgerald M, Gallagher L, Gill M. 2005. Preferential transmission of paternal alleles at risk genes in attentiondeficit/hyperactivity disorder. Am J Hum Genet 77 (6):958-965.

Hitchins MP, Bentley L, Monk D, Beechey $C$, Peters J, Kelsey G, Ishino F, Preece MA, Stanier P, Moore GE. 2002. DDC and $C O B L$, flanking the imprinted GRB10 gene on 7p12, are biallelically expressed. Mamm Genome 13 (12):686-691.

Jaenisch R, Bird A. 2003. Epigenetic regulation of gene expression: How the genome integrates intrinsic and environmental signals. Nat Genet 33 (Suppl):245-254.

Jirtle RL. 2002. www.geneimprint.com. 
Kent L, Green E, Hawi Z, Kirley A, Dudbridge $F$, Lowe $N$, Raybould $R$, Langley $\mathrm{K}$, Bray $\mathrm{N}$, Fitzgerald $\mathrm{M}$, et al. 2005. Association of the paternally transmitted copy of common Valine allele of the Val66Met polymorphism of the brain-derived neurotrophic factor (BDNF) gene with susceptibility to ADHD. Mol Psychiatry 10 (10):939-943.

Kim JW, Waldman I, Faraone S, Biederman J, Doyle AE, Purcell S, Arbeitman L, Fagerness J, Sklar P, Smoller JW. 2007. Investigation of parent-of-origin effects in ADHD candidate genes. Am J Med Genet Part B 144 (6):776-780.

Laurin N, Feng J, Ickowicz A, Pathare T, MaloneM, Tannock $\mathrm{R}$, Schachar $\mathrm{R}$, Kennedy JL, Barr CL. 2007. No preferential transmission of paternal alleles at risk genes in attention-deficit hyperactivity disorder. Mol Psychiatry $12(3): 226-229$.

Laurin N, Ickowicz A, Pathare T, Malone $M$, Tannock R, Schachar R, Kennedy JL, Barr CL. 2007. Investigation of the $G$ protein subunit G-alpha(olf) gene (GNAL) in attention deficit/ hyperactivity disorder. J Psychiatry Res (in press).

Mill J, Richards S, Knight J, Curran S, Taylor E, Asherson P. 2004. Haplotype analysis of SNAP-25 suggests a role in the aetiology of ADHD. Mol Psychiatry 9 (8):801-810.

Polanczyk G, de Lima MS, Horta BL, Biederman J, Rohde LA. 2007. The worldwide prevalence of ADHD: A systematic review and meta-regression analysis. Am J Psychiatry 164 (6):942948.

Purcell S, Neale B, Todd-Brown K, Thomas L, Ferreira MAR, Bender D, Maller J, de Bakker PIW, Daly MJ, Sham P. 2007. PLINK: A toolset for whole-genome association and population-based linkage analysis. Am J Hum Genet 81 (3):559-575.

Robertson KD. 2005. DNA methylation and human disease. Nat Rev Genet 6 (8):597-610.

Thapar A, Holmes J, Poulton K, Harrington R. 1999. Genetic basis of attention deficit and hyperactivity. Br J Psychiatry 174:105-111.

Walther DJ, Peter JU, Bashammakh S, Hortnagl $H$, Voits $M$, Fink $H$, Bader $M$. 2003. Synthesis of serotonin by a second tryptophan hydroxylase isoform. Science 299 (5603):76.

Weinberg CR. 1999. Methods for detection of parent-of-origin effects in genetic studies of case-parents triads. Am J Hum Genet 65 (1):229-235 